\title{
Dentistry
}

\section{Comparison of Four Different Irrigating Solutions on Dentinal Debris Removal}

Jorge Paredes Vieyra*

Department of Endodontics, Autonomous University of Baja California, California 92173, United States

\begin{abstract}
Aim: The aim of this research was to compare the dentinal debris removal capacity of $17 \%$ EDTA, $2.5 \% \mathrm{NaOCl}$, MTAD and $2 \%$ Clorhexidine when used as an irrigants throughout root canal instrumentation.

Methodology: Eighty maxillary incisors were used and allocated into four groups and instrumented with the same clinical procedure but rinsed with a different irrigant solution.

Results: Irrigating solutions employed were: 17\% EDTA, MTAD, 2.5\% NaOCl and 2\% Clorhexidine. After irrigation with: EDTA and MTAD resulted in little debris residual on canals as related with $\mathrm{NaOCl}$ and Clorhexidine. $\mathrm{NaOCl}$ left little debris on canals as compared with Clorhexidine but the difference was not statistically major. The Q-Cochran test showed statistical significance among the four groups. As the results for each group did not follow a normal distribution, the variables were analyzed using a nonparametric test. The level of statistical significance was set at $p<0.05$.
\end{abstract}

Conclusion: The final third of the canals revealed more debris than the two coronal canal and any of the irrigant employed left a clean canal in $100 \%$.

Keywords: Clean and shape; Debris; mtad; Chlorhexidine; EDTA; Biofilm

\section{Introduction}

Remove all the material inside the canal is a necessity for success of the root canal procedures. However, limitations of debridement by hand and mechanical way have been reported in recent studies $[1,2]$. The internal anatomy of the canals and lack of practice of the clinician predispose to transport the main canal, perforations and apical blockage [3-5].

Removal of debris, microorganisms and other inorganic material from the main canal previous obturation is an important tool to consider of the major targets of root canal therapy [6,7]. Microorganisms persisting in the canal space following clinical events or re-colonizing the obturated canal, are the principal source of failure [8].

Many studies concluded that manual nor rotary preparation does not remove debris and other toxic products of the root canal. There are some solutions such as $\mathrm{NaOCl}$ that are helpful in dissolve this type of material [9]. The efficiency of cleaning inside the canal relies on the real action of irrigant used. Copious flush plays a main part in an effective elimination of debris, and the best used irrigant for canals is $0.5 \%$ $5.25 \% \mathrm{NaOCl}[9]$.

Sodium hypochlorite $(\mathrm{NaOCl})$ appears to be the best solution with a wide range of properties than any other recognized mixture for this clinical purpose. Sodium Hypochlorite has capacity to melt necrotic tissue [10].

Neutralization of lipo-polysaccharides by $\mathrm{NaOCl}$ has been stated $[11,12]$; the influence, however, is slight related to that of a $\mathrm{Ca}(\mathrm{OH})_{2}$ covering [13]. Acid mixtures have the property to eradicate debris, involving EDTA, most active at a concentration of 15 to $17 \%$ [10]; citric acid solutions, used at concentrations of $10 \%$ to $50 \%[14,15]$.

EDTA shows low $\mathrm{Ph}$ and great potential in eliminate the smear layer $[16,17]$. This may describe why an EDTA acting as an irrigant showed superior properties in decreasing intracanal organic and inorganic material [18], but with a lower antiseptic capability [19].

Disinfectants such EDTAC [20] or MTAd [21] have been studied and reported with a high disinfectant and antimicrobial capacity.
EDTAC displays similar usefulness as EDTA, nonetheless it is more toxic [21]. An advantage of $17 \%$ EDTA against MTAD, is its substantive properties against anaerobic bacteria [21]. Irrigating solutions became an aid to eliminate bacteria from the canals and possible associations between them are a good tool for the clinician [22].

MTAD was used to eradicate smear layer [21], smear-layer on cervical leak of obturated canals using a dye leakage test [23].

Another solution for this purpose is chlorhexidine. It is a solid base and is very constant in the usage of its salts and they are fairly solvable in $\mathrm{H}_{2} \mathrm{O}$ [24]. Hereafter, they have been substituted by chlorhexidine (CLX). CLX is a strong disinfectant [25,26], and $2 \%$ is the ideal concentration of this irrigating solution for the canals [27].

The aim of the present scientific report was to compare the debris elimination capacity of $17 \%$ EDTA, $2.5 \% \mathrm{NaOCl}$, MTAD and $2 \%$ Clorhexidine when used as an irrigating solution throughout root canal instrumentation.

\section{Methodology}

This research was conducted with the agreement of the institutional review board.

\section{Tooth selection}

Eighty maxillary anterior teeth with a single canal taken from 35 to 61 year old patients with periodontal infection and randomly chosen and digitally radiographed. The teeth were lacking of decay, fissures, filled canals, or restorations. Teeth with complete apices, free of

*Corresponding author: Jorge Paredes Vieyra, Professor of Department of Endodontics, Autonomous University of Baja California, 710 E San Ysidro Blvd \# 1513, San Ysidro. CA, San Ysidro, California 92173, United States, Tel: 6195923431; E-mail: jorgitoparedesvieyra@hotmail.com

Received July 14, 2018; Accepted July 28, 2018; Published July 31, 2018

Citation: Vieyra JP (2018) Comparison of Four Different Irrigating Solutions on Dentinal Debris Removal Retreatment. Dentistry 8: 503. doi:10.4172/21611122.1000503

Copyright: (c) 2018 Vieyra JP. This is an open-access article distributed under the terms of the Creative Commons Attribution License, which permits unrestricted use, distribution, and reproduction in any medium, provided the original author and source are credited. 
Citation: Vieyra JP (2018) Comparison of Four Different Irrigating Solutions on Dentinal Debris Removal Retreatment. Dentistry 8: 503. doi:10.4172/2161-1122.1000503

Page 2 of 4

resorption and no root canal filled were included in the research. Teeth were placed in separate recipients with $2 \%$ formalin and maintained refrigerated at $10^{\circ} \mathrm{C}$. The average root length of the sample was $12 \mathrm{~mm}$ (Table 1).

\section{Root canal preparation}

All teeth were standardized by cutting the crown and with a root length of $12 \mathrm{~mm}$, and divided in four groups $(\mathrm{n}=20)$. Working lengths were calculated by subtracting $1 \mathrm{~mm}$ from measurements recorded once the tip of size \#10 K-files (Dentsply Maillefer, Ballaigues, Switzerland) stayed detectable at the final third and viewed roentgenographically. The canals were enlarged by rotary manner starting by size 25 LightSpeed LSX instrument (LightSpeed LSX, Sybron Endo, Culver City, USA).

Rotary debridement was started with size \#25 to size \#80 LightSpeed LSX instruments in the apical third. They were used with a $2000 \mathrm{rpm}$ (LightSpeed electric handpiece, Discus Dental, Culver City USA) using in and out movement. Each instrument was changed every 4 canals and the clinical procedures was achieved rendering to the company's directions. All the canals were flushed with $2 \mathrm{cc}$ of sanitized water.

Gates Glidden drills (Mani, Japan) \#1 to \#3 were used on the cervical and middle thirds before apical preparation.

\section{Irrigation}

Final irrigation was performed with 4 irrigating solutions by using an endodontic needle (30-gauge, Stropko Flexi-Tip; SE, Orange, CA), by penetrating 1-2 $\mathrm{mm}$ of the calculate length.

After cleaning and shaping the root canals have been flushed with 2 cc of respective irrigating solution: 17\% EDTA (Roth Int. Ltd., Chicago, IL), 2.5\% NaOCl, MTAD (BioPure MTAd; Dentsply, Tulsa, OK) and Clorhexidine (2.0\%). The canals were desiccated with sterile absorbent cones (Dentsply Maillefer).

\section{Scanning electronic microscopic analysis}

Teeth were sectioned longitudinally and estimated by thirds. Teeth were divided in labial-palatal level. To simplify separation in 2 pieces, the roots were fluted with the same manner on the exterior side using a metallic thin disk, taking care of canals.

The roots were chiseled and divided in two equal portions. The portion with the perceptible cut of the roots' top was preserved and encoded. The selected portions were placed on metallic stumps with compound, dried, covered with gold, subsequently observed with SEM (LEO 1430 VP. Carl Zeiss, Oberkochen, Ge).

Each third were scored and photographed at 1500 of magnification at the same elevation as the furrow that defined each third. The counting process was done by the author, the group of specimen was unknown using the following 5 score system [4].

Count 1: Clean canal wall; few debris particles.

Count 2: Small accumulations.

Count 3: Many accumulations; $<50 \%$.

Count 4: $>50 \%$.

Count 5: Full of debris.

\section{Results}

The results indicated that the proliferation in the percentage of debris and bacteria often happens in the similar way, i.e., from the cervical section to the end, independently which type applied. Tables
1 and 2 shows the amount of debris and the contrasts between the four solutions used.

EDTA group showed important changes among the other groups. EDTA was efficient in debris elimination than the rest of the irrigant solutions (Table 2).

\section{Statistical analysis}

The experimental records employed in this research comprised of 4 units with nonparametric Cochran analysis [28]. The statistical analysis indicated a statistical significance between the four groups. The level of probability was established as $\mathrm{p}<0.05$.

To describe which of the irrigating solutions was considerably dissimilar among groups, Tukey test was employed for this dissimilarity. Tukey test exhibited a difference among 2\% Clorhexidine and 17\% EDTA. Meanwhile 17\% EDTA and Biopure MTAD were found with similarities in reduction of debris.

Cervical thirds were seen free of debris, but remain observable at the final third in all cases (Figures 1 and 2).

\begin{tabular}{|c|c|}
\hline Group & Irrigating solutions during root canal preparation $(\mathbf{n = 2 0})$ \\
\hline A & EDTA \\
\hline B & $2.5 \% \mathrm{NaOCl}$ \\
\hline C & Biopure MTAd \\
\hline D & Clorhexidine $(2 \%)$ \\
\hline
\end{tabular}

Table 1: Solutions used during root canal preparation.

\begin{tabular}{|c|c|c|c|}
\hline $\begin{array}{c}\text { GROUP/IRRIGATING } \\
\text { SOLUTION }\end{array}$ & APICAL THIRD & MIDDLE THIRD & $\begin{array}{c}\text { CERVICAL } \\
\text { THIRD }\end{array}$ \\
\hline EDTA $(\boldsymbol{n}=\mathbf{2 0})$ & $1.22 \pm 0.35$ & $1.15 \pm 033$ & $1.08 \pm 0.10$ \\
\hline NAOCL $(\boldsymbol{n = 2 0})$ & $1.94 \pm 0.45$ & $1.76 \pm 0.43$ & $1.76 \pm 0.43$ \\
\hline & $<0.001$ & 0.004 & $<0.001$ \\
\hline BIPURE MTAd $(\mathbf{n = 2 0})$ & $1.54 \pm 0.35$ & $1.55 \pm 0.39$ & $1.69 \pm 0.30$ \\
\hline & 0.545 & 0.076 & 0.708 \\
\hline CLORHEXIDINE $(\boldsymbol{n = 2 0})$ & $2.10 \pm 0.80$ & $2.15 \pm 0.96$ & $2.10 \pm 0.94$ \\
\hline & 0.064 & 0.33 & 0.082 \\
\hline
\end{tabular}

Note: $\square$ : arithmetical mean; s, standard deviation.

Table 2: Results of the debris removal between irrigating solutions $(x \pm s)$.

Cervical third:

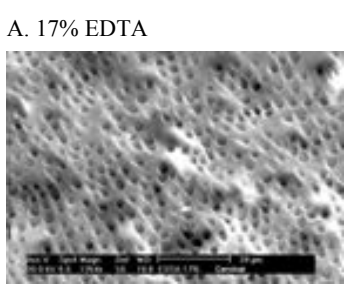

B. $\mathrm{mtad}$
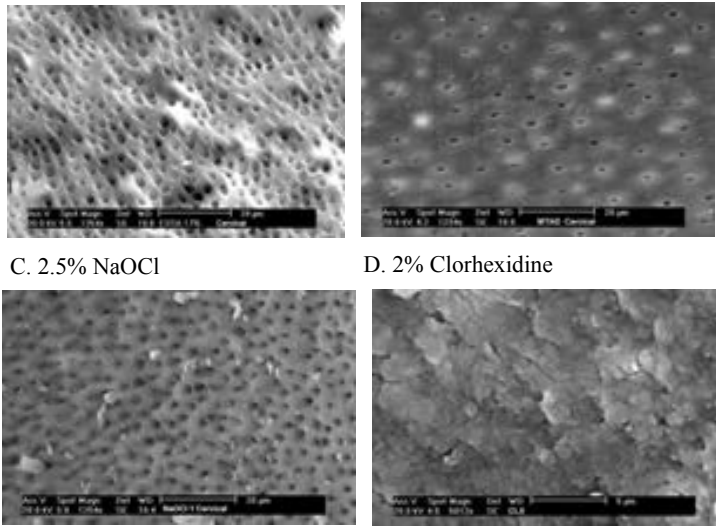

D. $2 \%$ Clorhexidine

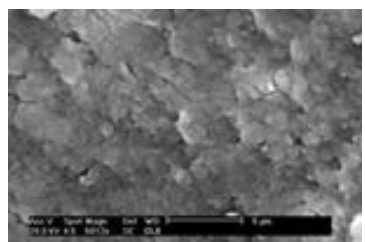

Figure 1. Typical SEM photomicrographs exhibiting the Cervical, Middle and apical thirds of root canal dentin surface in $17 \%$ EDTA, MTAD, $2.5 \% \mathrm{NaOCl}$ and $2 \%$ Clorhexidine $(1,000 x-5,000 x)$. 
Citation: Vieyra JP (2018) Comparison of Four Different Irrigating Solutions on Dentinal Debris Removal Retreatment. Dentistry 8: 503. doi:10.4172/2161-1122.1000503
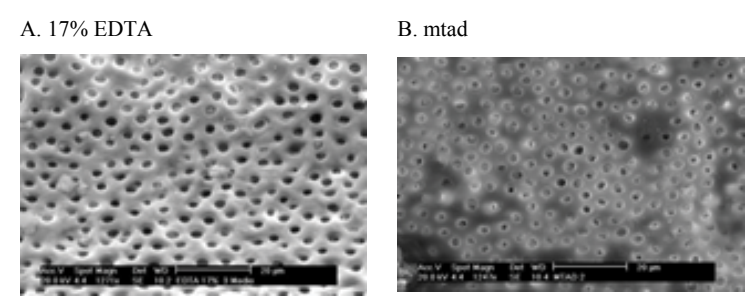

C. $2.5 \% \mathrm{NaOCl}$

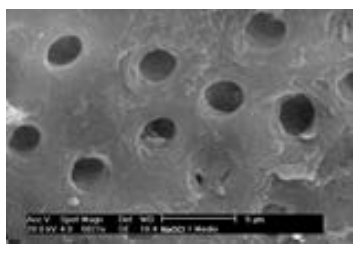

D. $2 \%$ Clorhexidine

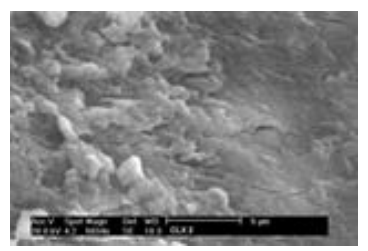

Figure 2: Middle third.

A. $17 \%$ EDTA

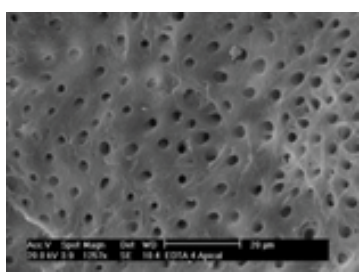

C. $2.5 \mathrm{NaOCl}$

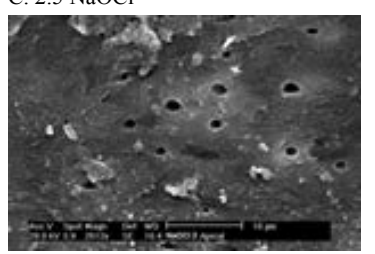

Figure 3: Apical Third.

\section{Discussion}

The aim of this research was to appraise the debris elimination capacity of $17 \%$ EDTA, $2.50 \% \mathrm{NaOCl}$, MTAD and $2 \%$ Clorhexidine when are employed as an irrigants during root canal procedures. The canal was analyzed and scored by thirds.

The combination of chemical and mechanical preparation is the key requisite for the achievement of the best eradication of debris. Irrigation has to be constant and copious to eliminate living/non-living materials.

$\mathrm{NaOCl}$ solution is the recommended solution to disinfect all type of material remnant [4]. However, in our study, $\mathrm{NaOCl}$ did not remove debris in the apical third, which is reliable with scores previously reported $[29,30]$.

Numerous authors $[16,19,20]$ described that alternating irrigants eliminate all kind of material inside the canal.

Hülsman et al. [6] did not find substantial changes in remains eradication, when they using $2.5 \% \mathrm{NaOCl}$ as an irrigant and $17 \%$ EDTA in pasteous consistence.

Our results show that EDTA and Biopure MTAD followed by $\mathrm{NaOCl}$ are effective irrigating solutions to decrease the amount of debris. Clorhexidine left considerable amount of debris. With the mechanical procedure, the outcomes for EDTA and the rest of the irrigants were comparable with earlier reports [9], and both solutions (EDTA and MTAD) are recommended (Figures 1 and 2).

EDTA solution removes debris and other material of the canal as reported by Tanomaru et al. [13] EDTA and $\mathrm{NaOCl}$ get a potentiation of the mixture action when energized by temperature [14]. Irrigating solutions employed in pulp therapy also clean the pulp chamber [11]. We found that any of the irrigating solutions reviewed was efficient of eliminating debris in $100 \%$ (Figure 3 ).

In our research, no relevant dissimilarities of existence of remains were detected between groups of instrumentation and flushed with $\mathrm{NaOCl}$. Our results are in concordance with Tucker [31] who compared mechanical instrumentation using $1 \% \mathrm{NaOCl}$ as irrigant.

To acquire disinfection through the canal thirds, current data is too heterogeneous to compare and identify superiority of an individual technique highlighting the need to standardize experimental protocols and develop a more representative research model to investigate the in vivo impact [32-35].

The reduction of debris has been discussed and reported in various scientific reports [32-35].

\section{Conclusion}

$17 \%$ EDTA and Biopure MTAD are irrigating solutions with high capacity to reduce debris better than $2.5 \% \mathrm{NaOCl}$ and $2 \%$ Clorhexidine.

\section{References}

1. Weine FS, Kelly RF, Bray KE (1976) Effect of preparation with endodontic handpieces on original canal shape. J Endod 2: 298-303.

2. Bolaños OR, Sinai IH, Gonsky MR, Srinivasan RA (1988) Comparison of engine and air driven instrumentation methods with hand instrumentation. $J$ Endod 14: 392-396.

3. Hülsmann M, Stryga $F$ (1993) Comparison of root canal preparation using different automated devices and hand instrumentation. J Endod 19: 141-145.

4. Hülsmann M, Rümmelin C, Schäfers F (1997) Root canal cleanliness after preparation with different endodontic handpieces and hand instruments: a comparative SEM investigation. J Endod 23: 301-306.

5. Bertrand MF, Pizzardini P, Muller M, Medioni E, Rocca JP (1999) The removal of the smear layer using the Quantec system: A study using the scanning electron microscope. Int Endod J 32: 217-224.

6. Hülsmann M, Schade $M$, Schafers $F$ (2001) A comparative study of root canal preparation with HERO 642 and Quantec SC rotary $\mathrm{Ni}$-Ti instruments. Int Endod J 34: 538-546.

7. Hülsmann M, Herbst $U$, Schäfers $F$ (2003) A comparative study of root cana preparation using Lightspeed and Quantec SC rotary Ni-Ti instruments. Int Endod J 36: 748-756.

8. Sjögren U, Figdor D, Persson S, Sundqvist G (1997) Influence of infection at the time of root filling on the outcome of endodontic treatment of teeth with apical periodontitis. Int Endod J 30: 297-306.

9. Zehnder M, Kosicki D, Luder H, Sener B, Waltimo T (2002) Tissue dissolving capacity and antimicrobial effect of buffered and unbuffered hypochlorite solutions. Oral Surg Oral Med Oral Pathol Oral Radiol Endod 94: 756-762.

10. Naenni N, Thoma K, Zehnder M (2004) Soft tissue dissolution capacity of currently used and potential endodontic irrigants. J Endod 30: 785-787.

11. Sarbinoff JA, O'Leary TJ, Miller CH (1983) The comparative effectiveness of various agents in detoxifying diseased root surfaces. J Periodontol 54: 77-80.

12. Silva LA, Leonardo MR, Assed S, Tanomaru Filho M (2004) Histological study of the effect of some irrigating solutions on bacterial endotoxin in dogs. Braz Dent J 15: 109-114.

13. Tanomaru JM, Leonardo MR, Tanomaru Filho M, Bonetti Filho I, Silva LA 
Citation: Vieyra JP (2018) Comparison of Four Different Irrigating Solutions on Dentinal Debris Removal Retreatment. Dentistry 8: 503. doi:10.4172/2161-1122.1000503

(2003) Effect of different irrigation solutions and calcium hydroxide on bacterial LPS. Int Endod J 36: 733-739.

14. Senia ES, Marshall FJ, Rosen S (1971) The solvent action of sodium hypochlorite on pulp tissue of extracted teeth. Oral Surg Oral Med Oral Pathol 31: $96-103$.

15. Garberoglio R, Becce C (1994) Smear layer removal by root canal irrigants A comparative scanning electron microscopic study. Oral Surg Oral Med Oral Pathol 78: 359-367.

16. Östby BN (1957) Chelation in root canal therapy. Odontol Tidskr 65: 3-11.

17. Lester KS, Boyde A (1977) Scanning electron microscopy of instrumented, irrigated and filled root canals. Braz Dent J 143: 359-367.

18. Zehnder M, Schmidlin P, Sener B, Waltimo T (2005) Chelation in root canal therapy reconsidered. J Endod 31: 817-820

19. Yoshida T, Shibata T, Shinohara T, Gomyo S, Sekine I (1995) Clinical evaluation of the efficacy of EDTA solution as an endodontic irrigant. J Endod 21: $592-593$.

20. Patterson SS (1963) In vivo and in vitro studies of the effect of the disodium salt of ethylene diamine tetra-acetate on human dentine and its endodontic implications. Oral Surg Oral Med Oral Pathol 16: 83-103.

21. Torabinejad M, Khademi AA, Babagoli J (2003) A new solution for the removal of the smear layer. J Endod 29: 170-175

22. Dahlén G, Samuelsson W, Molander A, Reit C (2005) Identification and antimicrobial susceptibility of Enterococci isolated from the root canal. Oral Microbiol Immunol 15: 309-312.

23. Saunders WP, Saunders EM (1992) The effect of smear layer upon the coronal leakage of gutta-percha fillings and a glass ionomer sealer. Int Endod J 25: 245-249.

24. McDonnell G, Russell AD (1999) Antiseptics and disinfectants: activity, action, and resistance. Clin Microbiol Rev 12: 147-179.
25. Foulkes DM (1973) Some toxicological observations on chlorhexidine. J Periodon Res 8: 55-60.

26. Addy M, Moran JM (1997) Clinical indications for the use of chemical adjuncts to plaque control: chlorhexidine formulations. Periodontol 2000 15: 52-54.

27. Zamany A, Safavi K, Spångberg LS (2003) The effect of chlorhexidine as an endodontic disinfectant. Oral Surg Oral Med Oral Pathol Oral Radiol Endod 96: 578-581.

28. Siegel S, Castellan NJ (1988) Non Parametric statistics for behavioral Sciences Mc Graw-Book Co. NY 240-261.

29. O'Connell MS, Morgan LA, Beeler WJ, Baumgartner JA (2000) A comparative study of smear layer removal using different salts of EDTA. J Endod 26: 739743

30. Di Lenarda R, Cadenaro M, Sbaizero O (2000) Effectiveness of 1 mol L-1 citric acid and 15\% EDTA irrigation on smear layer removal. Int Endod J 33: 46-52.

31. Tucker DM, Wenckus CS, Bentkover SK (1997) Canal wall planning by engine-driven nickel titanium instruments compared with stainless-steel hand instrumentation. J Endod 23: 170-173.

32. Virdee S, Seymour DW, Farnell D (2017) Efficacy of irrigant activation techniques in removing intracanal smear layer and debris from mature permanent teeth: a systematic review and meta-analysis. Int Endod J 51: 605-621.

33. Neelakantan P, Khan K, Li KY (2018) Effectiveness of supplementary irrigan agitation with the Finisher GF Brush on the debridement of oval root canals instrumented with the Gentlefile or nickel titanium rotary instruments. Int Endod J 51: 800-807.

34. Neelakantan P, Ahmed HMA, Wong MCM (2018) Effect of root canal irrigation protocols on the dislocation resistance of mineral trioxide aggregate-based materials: A systematic review of laboratory studies. Int Endod J 51: 847-861.

35. Ulusoy ÖI, Savur IG, Alaçam T, Çelic B (2018) The effectiveness of various irrigation protocols on organic tissue removal from simulated internal resorption defects. Int Endod J 1: 1-7. 